\title{
Efficacy of audiovisual distraction using eyeglasses during dental care: a randomized clinical trial
}

\author{
Natália Baschirotto CUSTÓDIO(a) iD \\ Mariana Gonzalez \\ CADEMARTORI(a) \\ Marina Sousa AZEVEDO(a) \\ Márcio de Almeida MENDES(b) iD \\ Lisandrea Rocha SCHARDOZIM(c) \\ Luciane Ribeiro de Rezende \\ Sucasas da COSTA(d) \\ Marília Leão GOETTEMS(a) \\ (a) Universidade Federal de Pelotas - UFPel, \\ School of Dentistry, Post-graduate program \\ in Dentistry, Pelotas, RS, Brazil. \\ (b) Universidade Federal de Pelotas - UFPel, \\ School of Dentistry, Post-graduate program \\ in Epidemiology, Pelotas, RS, Brazil.
}

(c) Universidade Federal de Pelotas - UFPel, Departament, of Social and Preventive Dentistry, Pelotas, RS, Brazil.

(d) Universidade Federal de Goiás - UFG, School of Dentistry, Post-graduate program in Dentistry and Health Sciences, Goiânia, GO, Brazil.

Declaration of Interests: The authors certify that they have no commercial or associative interest that represents a conflict of interest in connection with the manuscript.

Corresponding Author:

Marília Leão Goettems

E-mail: mariliagoettems@hotmaill.com

ht1ps://doi.org/10.1590/1807-3107bor-2021.vol35.0026

Submitted: May 14, 2020

Accepted for publication: October 30, 2020

Last revision: December 3, 2020
Abstract: This randomized parallel-group control trial tested the efficacy of distraction using audiovisual eyeglasses (AVE) during dental procedures [NCT03902158]. Forty-four 6-9 year-old children with low/moderate anxiety and who needed restorative treatment or exodontia of the primary molars were randomly allocated into two groups: the AVE (experimental) and the conventional behavior management techniques (control) groups. Motion sensors were used to measure the participants' body movements. Dental visits were video recorded, and their pain levels and behavior were assessed using the Faces, Legs, Activity, Cry, and Consolability Behavioral Pain Assessment Scale and the Venham Behavioral Scale, respectively. Anxiety was assessed via heart rate measurements. After treatment, the children scored their pain using the Faces Pain Scale. Mann-Whitney $U$ and chi-square tests were used to compare the groups. The mean score on the behavioral scale was 0.59 in the experimental group and 0.72 in the control group under local anesthesia $(p=0.73)$. During the procedure, the mean score was 0.41 in the experimental group and 1.32 in the control group ( $p=0.07)$. The mean heart rate was similar in both groups $(p=0.47)$, but a significant increase during treatment was observed in the control group. There was no difference between the groups in terms of pain, behavior, and self-reported pain scores $(p=0.08)$. Children aged 6-7 who used the AVE had fewer wrist movements (435.6) than that of children in the control group (1170.4) $(p=0.04)$. The AVE achieved similar results to the basic behavior management techniques, with good acceptance by the children.

Keywords: Dental Anxiety; Pain Perception; Child Behavior; Pediatric Dentistry; Randomized Controlled Trial.

\section{Introduction}

An important aspect of pediatric dentistry is the special attention given to children's wellbeing during the execution of dental treatments. Anxiety may be experienced by children during dental visits and manifest as noncompliant behaviors, which becomes a barrier to effective clinical practice. In addition, negative dental experiences in childhood, including toothaches, rough treatments by dentists, noise generated by dental equipment, and anesthetic needles are associated with high fear levels in 
adulthood. ${ }^{1}$ Among the procedures, local anesthesia, which is often required in dental treatments, has been reported as one of the main factors that trigger children's fear and anxiety. ${ }^{2}$

In this context, behavioral and anxiety management, as well as adequate pain control, are of the utmost importance to achieve success during the dental care of children, ${ }^{3}$ which can help to promote a positive attitude towards dentists and dental treatments. Distractions, which are indicated for behavioral management during short invasive procedures, ${ }^{4}$ involve a cognitive-behavior approach that seeks to divert the child's attention from what may be perceived as unpleasant stimuli and focus it on more pleasurable stimuli. Possible distraction tools include watching television, reading stories, playing with toys, listening to music, and the use of audiovisual eyeglasses (AVE). Although distractions are widely used during dental visits to provide a more relaxed experience and effective treatment for children, ${ }^{5}$ few studies have been performed on this subject that use adequate designs to observe the pain and anxiety outcomes in children. A systematic review found that most of the evaluated distraction techniques had significant effects on reducing anxiety and fear levels at some point during dental treatments, but the evidence had a low certainty. ${ }^{6}$

An audiovisual distraction, an eyeglasses system composed of a head-mounted display placed in front of the eyes and in-ear headphones, could be superior to traditional distraction methods as it is not only more engaging but also has the capability to block real-world visual and auditory stimuli. A systematic review ${ }^{7}$ showed that there is some low-quality evidence suggesting that the use of audiovisual distractions during dental treatment may relieve children's anxiety related to dental treatment. In addition, to verify their conclusions, the authors recommended high-quality studies to minimize the high risk of bias, such as those related to allocation concealments, the blinding of the outcome assessments, and incomplete or selective outcome data reports, that was identified in the included studies. A recent systematic review with a meta-analysis ${ }^{8}$ that included nine studies showed that the use of virtual reality (VR) glasses is an effective tool for improving behavior and reducing pain perception during dental treatments in children. The evidence was classified as moderate for most outcomes; however, evidence regarding some outcomes was insufficient and was not evaluated.

Ideally, a parallel group design should be adopted to avoid a carry-over effect between groups when a split-mouth design is used..$^{9}$ In addition, it is important to compare the technique with standard non-pharmacological behavioral techniques and use adequate measures to assess the outcomes. Considering that more robust and well-executed randomized clinical trials are still needed, ${ }^{6}$ the objective of this study was to test the efficacy of audiovisual distractions using VR eyeglasses compared to conventional behavior management techniques during procedures requiring local anesthesia.

\section{Methodology}

\section{Study design and participants}

This randomized parallel controlled trial was carried out between March and December 2018 in the Behavior Laboratory of the Infant Clinic Unit of the Dental School of Federal University of Pelotas. The laboratory has a room for interviews and a dental office, isolated from the rest of the clinic; it was prepared to allow video recording of the treatments. All procedures were approved by the local Human Research Ethics Committee (No. 2.407.669), and written consent was obtained from the parents of all the participants. It was registered in the clinicaltrials.gov registry under the identification number NCT03902158. This study is reported based on the CONSORT Statement guidelines. ${ }^{10}$

The minimum sample size was estimated based on a previous study, ${ }^{5}$ which found an average Venham behavior scale score of 0.14 (standard deviation [SD] 0.36 ) in children who used AVE during anesthesia and 0.75 (SD 0.52) in children who did not use it. A minimum sample size of 18 children in each group was estimated to allow detection of such differences, considering a power of $80 \%$ and a significance level of $5 \%$. To compensate for possible losses, the number was increased to a total of 22 children in each group. The sample consisted of children aged 6 to 9 years, who needed restorative treatments or exodontia 
of the primary molars under local anesthesia. All children were in good general health, had not received local anesthesia within the last 2 years, and did not have any previous experiences using virtual stereo glasses. Children with physical disabilities or mental deficiencies and those whose parents reported uncooperative behaviors (did not allow treatment in previous visits) were excluded. Children with high anxiety according to the Modified Venham Picture Test (VPTM) ${ }^{11}$ were excluded because they would probably require other behavior management techniques than the ones adopted in the study.

\section{Experimental design}

The children selected were attended to by one dentist (N.B.C.), a post-graduate student in pediatric dentistry, and an assistant. All children from both groups were scheduled for an initial consultation, which involved an interview regarding the participants' socio-demographic characteristics, an assessment of the child's anxiety level using VPTM with the child separated from parents, a clinical examination, and an oral hygiene orientation.

At the final visit, according to their dental needs (restorative treatment or exodontia), children were randomly assigned using sealed envelopes containing the group allocation: group 1 received dental treatments while using AVE during the consultation (intervention) and group 2 received dental treatments without AVE. After the allocation, in the first visit, children in the intervention group were asked to choose one out of three cartoon films that were suitable for all audiences (PJ Masks, Disney Fairies, or Ben 10). ${ }^{12}$ To select the three cartoon films, interviews were conducted about cartoon preferences with patients of the clinic in the same age range who were not included in the study.

In the second visit, the restorative treatment or exodontia of the primary molars was conducted according to the treatment needed. The infiltration technique was used for the administration of local anesthesia in the maxillary arch, and the inferior alveolar nerve block technique was used in cases where the lower arch was involved. For both groups, the dentist provided age-appropriate explanations about the procedure in layman's terms using basic techniques of behavior management ("tell-show-do" and positive reinforcement techniques). ${ }^{13}$ In the intervention group, the 98 -inch virtual stereo glasses HDMI-MHL model (98') was used, which played the cartoon film that was previously selected by the children.

The primary outcome of the study was the children's behaviors during the administration of local anesthesia and during the procedure. Secondary outcomes included anxiety, pain, behavior, body movements, and pain perception. The children's perceptions of the AVE and possible discomfort were also evaluated.

The Venham Scale ${ }^{14}$ was used to evaluated the behavior at each moment of the consultation; the child receives a score for their behavior according to the reactions presented. Scores range from zero (total cooperation) to a score of five (generalized protests). Children were assessed in different instances during the appointment: at the beginning (including after separation from their mother), during the local anesthesia, during the treatment procedure, and at the conclusion. The peak score, which consisted of the most negative score evaluated during the consultation, was also considered.

The Brazilian version of the Faces, Legs, Activity, Cry, and Consolability (FLACC) Behavioral Pain Assessment Scale was used to evaluate the children's pain during the procedure..$^{15}$ The scale includes the five categories of behavior and each category is scored from zero to two points, which results in a total score between 0 and 10. A score of 0 indicated that the child was relaxed and comfortable, scores from 1 to 3 indicated mild pain, scores from 4 to 6 indicated moderate pain, and scores from 7 to 10 indicated severe pain. The score was obtained by considering the entire visit and the time that the local anesthesia was administered.

The objective measure of anxiety was the children's heart rates, measured via oximetry. The Finger Pulse Oximeter MD300C1 by ChoiceMMed was placed on the index fingers of the children, and heart rate was monitored throughout their dental treatments. The mean heart rates during the anesthesia and the procedure and their heart rate changes were used as measures of anxiety. 
Body movements during the dental treatments, one of the outcomes of the study, were evaluated using accelerometers (ActiGraph wGT3X-BT, Pensacola, USA). The accelerometer measures body movements on three orthogonal axes, namely the vertical (Y), horizontal right-left $(X)$, and horizontal front-back axes $(Z){ }^{16}$ The devices were programmed to collect movement accelerations with a sampling frequency of $60 \mathrm{~Hz}$ (i.e., 60 measurements in each axis per second) and worn on the dominant wrists and the left legs of the subjects. The accelerometer setup, data download, and analyses were performed using ActiLife software, version 6.13.3 (Pensacola, USA). The accelerometer data were expressed in counts per minute (cpm, which consists of filtering the acceleration signals that are analogue to digital signals, using an algorithm specific from the manufacturer) and analyzed with a 5-second epoch length (i.e., for every 300 measurements taken in $5 \mathrm{~s}$, the summary of these records was condensed into just one measurement). ${ }^{16}$

After finishing the treatment, pain perception was measured using the Faces Pain Scale-Revised (FPS-R scale). ${ }^{17}$ The FPS-R scale evaluates the intensity of the child's pain using six aligned faces with expressions of pain in an increasing ordinal gradation, without crying or smiling expressions; its score ranges from zero (no pain) to 10 (severe pain). The FPS-R is indicated for children aged four and above, and its usage is accompanied by the following explanation: "These faces show how much something can hurt. This face [point to face on far left] shows no pain. The faces show more and more pain [point to each from left to right] up to this one [point to face on far right] - it shows very much pain. Point to the face that shows how much you hurt [right now]. This variable was dichotomized at zero with no pain and from two to 10 with pain.

At the end of the consultation, children who used the intervention were asked: "Did you enjoy watching the cartoon?" and "Would you like to watch it again?" with the objective of evaluating the child's perception about the use of AVE. The children were also asked about the discomfort experienced while using the AVE.

Owing to the impossibility of blinding the operator, behavior evaluator, and participants in terms of the use of the device, the operator and evaluator were blinded to the questionnaire and other study outcomes. Interviewers were also blinded to the participants' groups and test results achieved during the dental treatments. The person responsible for the statistical analysis was blinded to the groups.

\section{Training and calibration process}

As mentioned above, the dental treatments were performed by a dentist and an assistant. A team of three dental students collected data after undergoing a two-hour training on how to conduct the interview, the tests, and how to use the pulse oximeter and accelerometer. One dental student was responsible for administering the questionnaires to the mothers. The second was responsible for administering the VPTM and evaluating the FPS-R scale scores for the children. The third student recorded the heart rate during the dental treatments and placed the accelerometers. Dental visits were recorded on video and a professional with a PhD in pediatric dentistry and previous experience in behavior assessments, considered the gold standard for this type of assessment, assessed the children's behavior during the treatments using the Brazilian version of the Venham's Behavior Rating Scale (Venham Scale) ${ }^{14}$ and the FLACC scale. ${ }^{15}$ Prior to data collection, the evaluator was calibrated by evaluating the video recordings of 10 children receiving dental treatment and then re-evaluating them after 10 days. The weighted kappa for the FLACC Scale was 0.7 , with an agreement of $93 \%$, and the kappa value for the Venham Scale was 0.9, with an agreement of $98.5 \%$.

\section{Data analysis}

The data were double entered into a spreadsheet in the Microsoft ${ }^{\circledR}$ Excel ${ }^{\circledR} 2016$ program and analyzed using the Stata 14.0 program (StataCorp, College Station, USA). Neither the typist nor those who analyzed the data had previous knowledge about the group allocations. Initially, descriptive data analysis was performed to obtain the absolute and relative frequencies. Comparisons of the outcomes of interest between groups were made using a chi-square test for dichotomous variables, and Mann-Whitney $U$ test was used for the comparison 
of the means. A Wilcoxon paired test was used to compare the heart rate and behavior measures before and during the procedure. A significance level of $5 \%$ was adopted for all analyses.

\section{Results}

The flowchart of the participant selection is shown in Figure 1. In total, 44 children ( 24 boys and 20 girls) were included in the study. The mean age of the children was 7.7 (SD 0.96) years. The descriptive data are shown in Table 1. Three children in the control group received local anesthesia but did not finish their treatment and were excluded from the analyses of the outcomes that evaluated the whole visit. There was no difference between the dental procedures (exodontia and restorative treatments) and the teeth treated between the groups $(p=0.405$ and $p=0.380$, respectively) (data not shown).

The behavior scores, based on the Venham Behavioral Scale, at different time points are shown in Table 2. During anesthesia, the mean score on this scale was 0.59 for the AVE group and 0.72 for the control group $(\mathrm{p}=0.73)$, and the mean scores during the procedure was 0.41 in the intervention group and 1.32 in the control group $(p=0.07)$. Regarding the within group analysis, the score increase during anesthesia was significant in both groups.

Table 3 shows the anxiety scores that were evaluated based on the heart rates recorded while the children were under local anesthesia and throughout the procedure. While under local anesthesia, the mean heart rate was $95.41 \mathrm{bpm}$ in the AVE group and $98.86 \mathrm{bpm}$ in the control group $(\mathrm{p}=0.45)$. Compared to that at the beginning of the visits, the increase in heart rate seen during anesthesia and the treatment was higher in the control group, but the difference was not statistically significant (Table 3).

Figure 2 shows the mean heart rates measured during the different moments of the dental visit for each group. The increase was significant in the control group $(p=0.050)$ but not in the AVE group $(p=0.346)$.

The mean FLACC score was 2.23 in the intervention group and 3.11 in the control group $(p=0.79)$ during the procedure. During anesthesia, the FLACC score was 1.45 in the AVE group and 2.11 in the control group ( $p=0.23$ ). Pain was reported by five children in the control group and by one child in the AVE group $(p=0.08)$ (Table 4$)$.

The accelerometer analysis showed no significant differences between groups in terms of arm movements and leg movements. The stratified analysis showed

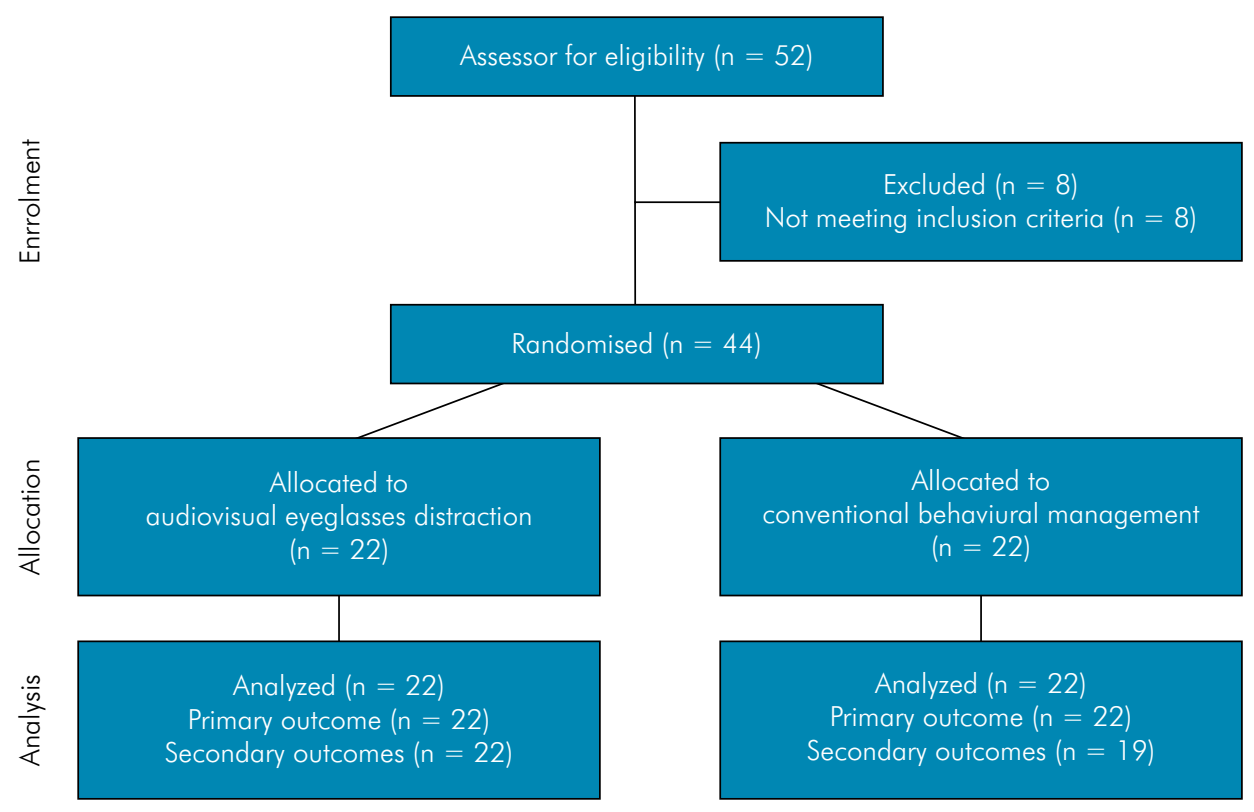

Figure 1. Flowchart of the participants selection. 
Efficacy of audiovisual distraction using eyeglasses during dental care: a randomized clinical trial

Table 1. Descriptive characteristics of groups according to the use of audiovisual eyeglasses (AVE) ( $n=44)$.

\begin{tabular}{|c|c|c|c|}
\hline \multirow{2}{*}{ Variable } & Total & Group 1 & Group 2 \\
\hline & $(n=44)$ & With AVE $(n=22)$ & Without AVE $(n=22)$ \\
\hline Age, mean $(S D)$ & $7.66(0.96)$ & $7.73(1.03)$ & $7.60(0.91)$ \\
\hline \multicolumn{4}{|l|}{ Age, n(\%) } \\
\hline $6-7$ years & $17(38.64 \%)$ & $8(36.4 \%)$ & 9 (40.9\%) \\
\hline $8-9$ years & $27(61.36 \%)$ & $14(63.6 \%)$ & $13(59.1 \%)$ \\
\hline \multicolumn{4}{|l|}{ Sex, $n(\%)$} \\
\hline Male & $24(54.6 \%)$ & $12(54.5 \%)$ & $12(54.5 \%)$ \\
\hline Female & $20(45.4 \%)$ & $10(45.5 \%)$ & $10(45.5 \%)$ \\
\hline \multicolumn{4}{|l|}{ Procedure, $n(\%)$} \\
\hline Restauration & $25(56.8 \%)$ & $13(59.1 \%)$ & $12(54.5 \%)$ \\
\hline Extraction & 19 (43.2\%) & 9 (40.9\%) & $10(45.5 \%)$ \\
\hline \multicolumn{4}{|l|}{ Teeth treated, n(\%) } \\
\hline Maxillary primary molars & $6(13.6 \%)$ & $2(9.1 \%)$ & $4(18.2 \%)$ \\
\hline Mandibular primary molars & $38(86.4 \%)$ & $20(90.9 \%)$ & $18(81.8 \%)$ \\
\hline \multicolumn{4}{|l|}{ Dental fear, $n(\%)$} \\
\hline No & 17 (38.6\%) & 7 (31.8\%) & $10(45.5 \%)$ \\
\hline Yes & $27(61.4 \%)$ & $15(68.2 \%)$ & $12(54.5 \%)$ \\
\hline \multicolumn{4}{|l|}{ Anxiety*, n(\%) } \\
\hline Low & $4(9.1 \%)$ & $1(4.5 \%)$ & $3(13.6 \%)$ \\
\hline Moderate & $40(90.9 \%)$ & 21 (95.5\%) & 19 (86.4\%) \\
\hline
\end{tabular}

*Modified Venham Picture Test (VPTM).

Table 2. Children behaviour according to Venham Scale during the local anaesthesia, during the procedure and peak score according to the use of audiovisual eyeglasses (AVE) $(n=44)$.

\begin{tabular}{|c|c|c|c|c|}
\hline \multirow{3}{*}{ Behavior (Venham scale) } & \multirow{3}{*}{ Total n (\%) } & Group 1 & Group 2 & \multirow{3}{*}{$p$-value } \\
\hline & & With AVE & Without AVE & \\
\hline & & $\mathrm{n}(\%)$ & n (\%) & \\
\hline During anaesthesia & & & & 0.73 \\
\hline Mean (SD) & $0.65(0.93)$ & $0.59(0.59)$ & $0.72(1.20)$ & \\
\hline Median (IQR) & $0(1-1)$ & $1(0-1)$ & $0(0-1)$ & \\
\hline During dental procedure & & & & 0.07 \\
\hline Mean (SD) & $0.83(1.53)$ & $0.41(0.96)$ & $1.32(1.92)$ & \\
\hline Median (IQR) & $0(0-1)$ & $0(0-0)$ & $0(0-2)$ & \\
\hline Peak score & & & & 0.59 \\
\hline Mean (SD) & $1.27(1.50)$ & $1.00(1.02)$ & $1.58(1.89)$ & \\
\hline Median (IQR) & $1(0-1)$ & $1(0-1)$ & $1(0-2)$ & \\
\hline$p$-value anesthesia-initial ${ }^{* *}$ & $<0.001$ & $<0.001$ & 0.003 & \\
\hline $\mathrm{p}$-value anesthesia-procedure ${ }^{* *}$ & 0.26 & 0.11 & 0.91 & \\
\hline
\end{tabular}

$\overline{I Q R}=$ Interquartile range; ${ }^{*}$ Mann-Whitney test; ${ }^{* *}$ Wilcoxon paired test.

that children aged 6-7 years who used the eyeglasses had fewer wrist movements (435.6) than that of children in the control group (1170.4) $(p=0.04)$, but had a similar number of leg movements (Table 5).
All children in the intervention group reported that they enjoyed watching the cartoons and would like to use the AVE again during other visits. No discomfort was reported using the AVE. 
Table 3. Mean, median and interquartile range (IQR) heart rate during the local anaesthesia and during the dental visit according to the use of audiovisual eyeglasses (AVE) $(n=44)$.

\begin{tabular}{|c|c|c|c|c|}
\hline \multirow{2}{*}{ Hearth rate (bpm) } & \multirow{2}{*}{ Total } & Group 1 & Group 2 & \multirow{2}{*}{$p$-value } \\
\hline & & With AVE & Without AVE & \\
\hline \multicolumn{5}{|l|}{ During the anaesthesia } \\
\hline Mean (SD) & $97.14(15.91)$ & $95.41(13.48)$ & $98.86(18.18)$ & 0.45 \\
\hline Median (IQR) & 98.5 & $95.5(86-103)$ & $101.5(86-106)$ & \\
\hline Changes in hearth rate & $5.61(2.81)$ & $3.77(3.22)$ & $7.45(4.59)$ & 0.29 \\
\hline \multicolumn{5}{|l|}{ During the procedure } \\
\hline Mean (SD) & $95.11(9.66)$ & $94.59(8.02)$ & $95.63(11.24)$ & 0.65 \\
\hline Median (IQR) & $97.4(89-100)$ & $97.3(90-98)$ & $98.3(86-101)$ & \\
\hline Changes in hearth rate & $2.95(9.92)$ & $1.23(2.79)$ & $4.68(3.82)$ & 0.25 \\
\hline
\end{tabular}

*Mann-Whitney test.

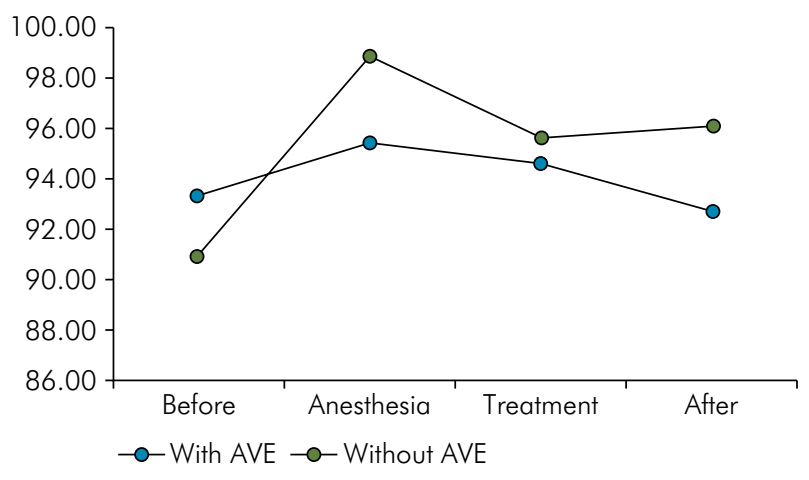

Figure 2. Mean hearth rate during the different moments of the dental visit according to the group.

\section{Discussion}

This randomized clinical trial evaluated the efficacy of audiovisual distractions and compared it to that of conventional behavior management techniques during procedures performed under local anesthesia. Our findings did not show statistically significant differences in either the subjective measures or objective measures. Children who used the AVE did not exhibit better behavior, less perception of pain, lower heart rates, or fewer body movements than those

Table 4. Pain perception evaluated using the Face, Legs, Activity, Cry and Consolability (FLACC) scale during the visit and following the procedure using the Faces Pain Scale revised (FPS-R) according to the use of audiovisual eyeglasses (AVE) $(n=44)$.

\begin{tabular}{|c|c|c|c|c|}
\hline \multirow{3}{*}{ Pain } & \multirow{2}{*}{ Total } & Group 1 & Group 2 & \multirow{3}{*}{$\mathrm{p}$-value } \\
\hline & & With AVE & Without AVE & \\
\hline & Mean (SD) & Mean (SD) & Mean (SD) & \\
\hline During the Procedure & & & & $0.79^{*}$ \\
\hline No/mild pain n (\%) & $31(75.6)$ & $17(77.3)$ & $14(73.7)$ & \\
\hline Moderate/severe pain n (\%) & $10(24.4)$ & $5(22.7)$ & $5(26.3)$ & \\
\hline Mean score (SD) & $2.63(2.43)$ & $2.23(2.18)$ & $3.11(2.66)$ & $0.79^{* *}$ \\
\hline During the anaesthesia & & & & $0.18^{*}$ \\
\hline No/mild pain & $28(68.3)$ & $17(77.3)$ & $11(57.9)$ & \\
\hline Moderate/severe pain & $13(31.7)$ & $5(22.7)$ & $8(42.1)$ & \\
\hline Mean score & $1.76(3.05)$ & $1.45(2.40)$ & $2.11(3.71)$ & $0.23^{* *}$ \\
\hline FPS - R scale following treatment & & & & $0.08^{*}$ \\
\hline No pain n (\%) & 38 (86.4\%) & 21 (95.5\%) & $17(77.3 \%)$ & \\
\hline Pain n (\%) & $6(13.64 \%)$ & $1(4.5 \%)$ & $5(22.7 \%)$ & \\
\hline Mean score (SD) & $0.45(1.42)$ & $0.08(0.41)$ & 0.9 (1.99) & $0.08^{* *}$ \\
\hline
\end{tabular}

*Chi-squared test; **Mann-Whitney test. 
Table 5. Body movements (counts per minute measurement - cpm) measured by accelerometers during the dental visit according to the use of audiovisual eyeglasses (AVE) $(n=44)$.

\begin{tabular}{lcccc}
\hline & & Group 1 & Group 2 \\
Accelerometry analysis (cpm) & Total & With AVE & Without AVE & p-value* \\
\cline { 2 - 3 } & Mean (SD) & Mean (SD) & Mean (SD) \\
\hline Dominant Wrist & & & & \\
Total sample & $802.0(601.9)$ & $676.5(432.0)$ & $911.52(748.7)$ & 0.46 \\
6-7 years & 824.6 & $435.6(204.7)$ & $1170.4(930.8)$ & 0.04 \\
8-9 years & 765.5 & $824.8(473.4)$ & $695.3(517.9)$ & 0.52 \\
Leg Mean (SD) & & & & \\
Total sample & $545.37(430.86)$ & $565.88(526.32)$ & $497.38(295.79)$ & 0.96 \\
6-7 years & $472.2(308.3)$ & $398.8(379.9)$ & $545.6(216.9)$ & 0.35 \\
8-9 years & $572.4(495.2)$ & $668.7(589.4)$ & $458.7(347.6)$ & 0.31 \\
\hline
\end{tabular}

*Mann-Whitney test.

of children in the control group did. The children in the present study received local anesthesia and were treated without sedation. The type of procedure can influence a child's behavior, and it is known that local anesthesia is considered by many children as a great source of fear and anxiety. ${ }^{18}$ This may be one of the reasons for the similar levels of anxiety in both groups. Notably, there were patients included in the study that, despite having low/moderate anxiety as measured by the VPTM during the initial visits, were anxious during the procedure and did not allow the procedure to be completed even while they were under the local anesthesia.

This was the first study to use accelerometer analysis to evaluate body movements during dental procedures. Given the fact that AVE increases children's distraction levels, it was hypothesized that children would have fewer movements during the treatment because the distraction technique could allow for greater relaxation ${ }^{3}$, therefor, reducing the number of body movements during their dental care. This outcome was confirmed only for children aged 6-7 years and should be confirmed in further studies with an appropriate sample size.

The findings of the present study corroborate those observed by Sullivan et al. ${ }^{19}$ and Al-Halabi and Zuhair Alnerabieah, ${ }^{20}$ in which the glasses failed to improve the behaviors of the children evaluated. According to the authors, the glasses blocked the real world and increased the child's anxiety about their current environment and the dental procedure being received. The children included in the studies were 6-9 years of age, and it is known that dental anxiety decreases with age. ${ }^{21}$ In addition, different age groups display different cognitive abilities and behavioral patterns. So far, systematic reviews have not compared the effect of audiovisual distractions between different age groups ${ }^{7,8}$. Regarding anxiety, another study using heart rate as an objective measure of anxiety reported no differences using the VR glasses. ${ }^{22}$ This discrepancy can be explained by the fact that the procedure was performed in the second consultation in our study; the child's anxiety was reduced because they were already familiar with the environment and had already been informed about the procedure by the dentist. In addition, it has been hypothesized that the device may cause discomfort for some children as it totally blocks their vision. In the present study, no children reported feeling any discomfort while using the eyeglasses.

One of the most important aspects of modulating child behavior is pain control. Pain is a sensation that involves sensory, emotional, and cognitive processes. Pain prevention can nurture the trust between the dentist and patient, relieve fear and anxiety, and improve positive dental attitudes in future visits. ${ }^{13}$ Children who experience pain during restorative or surgical procedures have an increased chance of having negative perceptions about dental treatments. ${ }^{23,24}$ In our study, no statistically significant 
differences were found in the perception of pain between the two groups evaluated using both scales. Children in both groups reported low levels of pain, which may reflect that the professional managed their pain quite well. The results are similar to those found by previous studies ${ }^{22,25}$ that evaluated the efficacy of VR glasses during restorative dental treatments in children. According to Hoge et al., ${ }^{25}$ video eyewear is more effective at distracting children from external stimuli (e.g., the sights and sounds of the operation) than from internal stimuli (e.g., sensations associated with dental treatments).

According to the American Academy of Pediatric Dentistry guidelines, ${ }^{13}$ most children can be managed effectively using the techniques outlined in the basic behavior guidance section, such as with proper communication techniques and nitrous oxide/oxygen administration, and should form the foundation for all of the management techniques attempted by a dentist. Studies evaluating communication techniques, especially distraction techniques, have incorporated new technologies, mainly because of the relevance they have to children and adolescents. Distractions using tablets, ${ }^{20,22}$ playing of video games ${ }^{26}$ or music ${ }^{27}$ on mobile phones, and $\mathrm{AVE}^{24,28,29,30}$ have been suggested. AVE completely block children's visual fields, which may be beneficial compared to other techniques. ${ }^{31}$ Given the ease of introducing distractions into clinical practice, the absence of any known deleterious effects, the potential for positive outcomes, and patient preference, the need for more systematic and widespread use of these techniques is reinforced. ${ }^{32}$ Thus, providing evidence for the efficacy of these techniques is important. Although there were no differences between groups in the present study, AVE proved to be a good alternative to conventional techniques for distracting children; this is because the results were similar to those obtained in the group of children who did not receive AVE. In addition, all the children reported that they liked to watch the cartoons and would like to use the AVE in other visits.

One of the limitations of this study was the impossibility of blinding the participants and the operator to the use of the device or the evaluator to the outcomes. However, in order to minimize this possible bias, the evaluator and operator were blinded to the outcomes of the questionnaires and other tests, such as the VPTM, and the person responsible for the statistical analyses was blinded to the groups and the other variables considered in this study. Another limitation of this study is that the sample size was calculated to test our main outcome (behavior), but it is possible that the power was too low for the secondary outcomes, which increases the probability of type II errors.

The present study has the following strengths: it was a randomized parallel-group clinical trial, the evaluation was performed by an experienced and calibrated researcher, making the evaluations more reliable, and the study was conducted in a controlled environment, the Behavior Laboratory, in order to minimize the influence of the external environment. In addition, basic behavioral management techniques were used in both groups, considering that communication techniques are applied universally in pediatric dentistry, in both cooperative and uncooperative children ${ }^{13}$. All these factors avoided introducing bias in the sample group but may have also contributed to the similarity between the groups. Studies with larger samples, different aged participants, and conventional clinical settings should be conducted in order to help substantiate the effectiveness of AVE and other distraction techniques.

\section{Conclusions}

AVEs are a pleasurable method of distraction, without adverse effects. These findings suggest that distraction with AVE can be used as a distraction technique, with results similar to that of conventional behavior management techniques typically recommended.

\section{Acknowledgements}

This work was supported by the Fundação de Amparo a Pesquisa do Estado do Rio Grande do Sul (FAPERGS); and by the Coordenação de Aperfeiçoamento de Pessoal de Nível Superior - Brasil (Capes) [Finance code 001]. 
Efficacy of audiovisual distraction using eyeglasses during dental care: a randomized clinical trial

\section{References}

1. Oliveira MA, Vale MP, Bendo CB, Paiva SM, Serra-Negra JM. Influence of negative dental experiences in childhood on the development of dental fear in adulthood: a case-control study. J Oral Rehabil. 2017 Jun;44(6):434-41. https://doi.org/10.1111/joor.12513

2. Majstorovic M, Veerkamp JS. Relationship between needle phobia and dental anxiety. J Dent Child (Chic). 2004 Sep-Dec;71(3):201-5.

3. Goettems ML, Zborowski EJ, Costa FD, Costa VP, Torriani DD. Nonpharmacologic intervention on the prevention of pain and anxiety during pediatric dental care: a systematic review. Acad Pediatr. 2017 Mar;17(2):110-9. https://doi.org/10.1016/i.acap.2016.08.012

4. McCaul KD, Malott JM. Distraction and coping with pain. Psychol Bull. 1984 May;95(3):516-33. https://doi.org/10.1037/0033-2909.95.3.516

5. Al-Khotani A. Bello LA, Christidis N. Effects of audiovisual distraction on children's behavior during dental treatment: a randomized controlled clinical trial. Acta Odontol Scand. 2016 Aug;74(6):494-501. https://doi.org/10.1080/00016357.2016.1206211

6. Prado IM, Carcavalli L, Abreu LG, Serra-Negra JM, Paiva SM, Martins CC. Use of distraction techniques for the management of anxiety and fear in paediatric dental practice: A systematic review of randomized controlled trials. Int J Paediatr Dent. 2019 Sep;29(5):650-68. https://doi.org/10.1111/ipd.12499

7. Liu Y, Gu Z, Wang Y, Wu Q, Chen V, Xu X, et al. Effect of audiovisual distraction on the management of dental anxiety in children: a systematic review. Int J Paediatr Dent. 2019 Jan;29(1):14-21. https://doi.org/10.1111/ipd.12430

8. Custódio NB, Costa FD, Cademartori MG, Costa VP, Goettems ML. Effectiveness of virtual reality glasses as a distraction for children during dental care. Pediatr Dent. 2020 Mar;42(2):93-102.

9. Gomes HS, Daher A, Costa PS, Batista AC, Costa LR. Crossover Studies of Pediatric Dental Sedation are Inappropriate. Braz Dent J. 2019 Jul;30(4):404-9. https://doi.org/10.1590/0103-6440201902852

10. Moher D, Hopewell S, Schulz KF, Montori V, Gøtzsche PC, Devereaux PJ, et al. CONSORT 2010 Explanation and Elaboration: updated guidelines for reporting parallel group randomised trials. J Clin Epidemiol. 2010 Aug;63(8):e1-37. https://doi.org/10.1016/i.jclinepi.2010.03.004

11. Ramos-Jorge ML, Marques LS, Pavia SM, Serra-Negra JM, Pordeus IA. Predictive factors for child behaviour in the dental environment. Eur Arch Paediatr Dent. 2006 Dec;7(4):253-7. https://doi.org/10.1007/BF03262561

12. Guinot Jimeno F, Mercadé Bellido M, Cuadros Fernández C, Lorente Rodríguez Al, Llopis Pérez J, Boj Quesada JR. Effect of audiovisual distraction on children's behaviour, anxiety and pain in the dental setting. Eur J Paediatr Dent. 2014 Sep;15(3):297-302.

13. American Academy Of Pediatric Dentistry. Guideline on behavior guidance for the pediatric dental patient. the reference manual of pediatric dentistry. Chicago: American Academy of Pediatric Dentistry; 2019.

14. Cademartori MG, Rosa DP, Oliveira LJ, Corrêa MB, Goettems ML. Validity of the Brazilian version of the Venham's behavior rating scale. Int J Paediatr Dent. 2017 Mar;27(2):120-7. https://doi.org/10.1111/ipd.12231

15. Silva FC, Thuler LC. Cross-cultural adaptation and translation of two pain assessment tools in children and adolescents. J Pediatr (Rio J). 2008 Jul-Aug;84(4):344-9. https://doi.org/10.2223/JPED.1809

16. ActiGraph Inc. Actilife users manual. Pensacola: ActiGraph; 2009.

17. Hicks CL, von Baeyer CL, Spafford PA, van Korlaar I, Goodenough B. The faces pain scale-revised: toward a common metric in pediatric pain measurement. Pain. 2001 Aug;93(2):173-83. https://doi.org/10.1016/S0304-3959(01)00314-1

18. Morgan AG, Rodd HD, Porritt JM, Baker SR, Creswell C, Newton T, et al. Children's experiences of dental anxiety. Int J Paediatr Dent. 2017 Mar;27(2):87-97. https://doi.org/10.1111/ipd.12238

19. Sullivan C, Schneider PE, Musselman RJ, Dummett Jr, CO, Gardiner D. The effect of virtual reality during dental treatment on child anxiety and behavior. ASDC J Dent Child. 2000May-June;67(3):193-6,160-1.

20. Al-Halabi MN, Zuhair Alnerabieah NB. Effectiveness of audio-visual distraction using virtual reality eyeglasses versus tablet device in child behavioral management during inferior alveolar nerve block. Anaesth Pain Intensive Care. 2018;22(1):55-61.

21. Locker D, Liddell A, Dempster L, Shapiro D. Age of onset of dental anxiety. J Dent Res. 1999 Mar;78(3):790-6. https://doi.org/10.1177/00220345990780031201

22. Mitrakul K, Asvanund Y, Arunakul M, Paka-Akekaphat S. Effect of audiovisual eyeglasses during dental treatment in 5-8 year-old children. Eur J Paediatr Dent. 2015 Sep;16(3):239-45.

23. McDonald RE, Avery DR, Dean JA, Jones JE. Local anesthesia and pain control for the child and adolescent. In: McDonald and Avery's Dentistry for the child and adolescent. Saint Lovis: Mosby; 2011. p. 241-52.

24. Ei-Sharkawi FA, El-Housseiny A, Mahmoud A. Effectiveness of new distraction technique on pain associated with injection of local anesthiesia for children. Pediatr Dent. 2012 Mar-Apr;34(2):e35-8.

25. Hoge MA, Howard MR, Wallace DP, Allen KD. Use of video eyewear to manage distress in children during restorative dental treatment. Pediatr Dent. 2012 Sep-Oct;34(5):378-82. 
26. Allani S, Setty JV. Effectiveness of distraction techniques in the management of anxious children in the dental operatory. IOSR J Dent Med Sci. 2016;15(10):69-73. https://doi.org/10.9790/0853-1510026973

27. Navit S, Johri N, Khan SA, Singh RK, Chadha D, Navit $P$, et al. Effectiveness and comparison of various audio distraction Aids in management of anxious dental paediatric patients. J Clin Diagn Res. 2015 Dec;9(12):ZC05-09. https://doi.org/10.7860/JCDR/2015/15564.691028

28. Asvanund Y, Mitrakul K, Juhong RO, Arunakul M. Effect of audiovisual eyeglasses during local anesthesia injections in 5- to 8-year-old children. Quintessence Int. 2015 Jun;46(6):513-21. https://doi.org/10.3290/i.qi.a33932

29. Nuvvula S, Alahari S, Kamatham R, Challa RR. Effect of audiovisual distraction with 3D video glasses on dental anxiety of children experiencing administration of local analgesia: a randomised clinical trial. Eur Arch Paediatr Dent. 2015 Feb;16(1):43-50. https://doi.org/10.1007/s40368-014-0145-9

30. Garrocho-Rangel A, Ibarra-Gutiérrez E, Rosales-Bérber M, Esquivel-Hernández R, Esparza-Villalpando V, Pozos-Guillén A. A video eyeglasses/earphones system as distracting method during dental treatment in children: A crossover randomised and controlled clinical trial. Eur J Paediatr Dent. 2018 Mar;19(1):74-9.

31. Asl Aminabadi N, Erfanparast L, Sohrabi A, Ghertasi Oskovei S, Naghili A. The impact of virtual reality distraction on pain and anxiety during dental treatment in 4-6 year-old children: a randomized controlled clinical trial. J Dent Res Dent Clin Dent Prospects. 2012;6(4):117-24. https://doi.org/10.5681/joddd.2012.025

32. Armfield JM, Heaton LJ. Management of fear and anxiety in the dental clinic: a review. Aust Dent J. 2013 Dec;58(4):390-407. https://doi.org/10.1111/adj.12118 